\title{
Producer's Preference for Price Instability: Revisited
}

\author{
Andrew Schmitz, Claudine Chegini \\ Department of Food and Resource Economics, University of Florida, Gainesville, Florida, USA \\ Email:aschmitz@ufl.edu,cchegini@ufl.edu
}

How to cite this paper: Schmitz, A., \& Chegini, C. (2020). Producer's Preference for Price Instability: Revisited. Theoretical Economics Letters, 10, 1193-1197. https://doi.org/10.4236/tel.2020.105070

Received: July 23, 2020

Accepted: October 26, 2020

Published: October 29, 2020

Copyright ( 2020 by author(s) and Scientific Research Publishing Inc. This work is licensed under the Creative Commons Attribution International License (CC BY 4.0).

http://creativecommons.org/licenses/by/4.0/

(c) (i) Open Access

\begin{abstract}
In the debate over producer preference for price instability, Oi argues that producers prefer price instability to stability using only the case where demand shocks generate instability. In this case, storage hurts producers. We use the classic welfare economic framework to consider the more likely scenario where instability is generated by supply shocks and, in the absence of storage, producers prefer production and price instability. However, producers can increase their profits by storing part of the production in the low-price period and releasing stocks in the high-price period. The strong conclusion is that producers prefer, on net, price stability to instability when the possibility for storage exists. Under profit maximization, producers, not governments, engage in storage. Producers prefer to produce under unstable prices, but to sell at stable prices. On net, producers prefer price stability.
\end{abstract}

\section{Keywords}

Producers, Price Instability, Private Storage

\section{Introduction}

The debate over both producers' preference for price instability and the economic effects of commodity storage has a long history (Schmitz et al., 2010). The early writings on these topics are grounded in classical welfare economics, where this approach provides the basis for empirical analyses. ${ }^{1}$ Oi (1961) was among

\footnotetext{
${ }^{1}$ In many less developed countries, governments engage in food stockholding activities where a major objective is food security. However, in our model food security is not implicitly considered. Storage under food insecurity is taken up elsewhere (Schmitz \& Kennedy, 2016; Kennedy, Schmitz, \& van Kooten, 2019; Kennedy, Schmitz, \& van Kooten, 2020; Schmitz, 2020; van Kooten, Schmitz, \& Kennedy 2020). In addition, our model does not consider the multiproduct case where, using a utility maximization framework, consumers, like producers, prefer stability for a subset of the total commodity bundle consumed and produced (Turnovsky, Shalit, \& Schmitz, 1980; Schmitz, Shalit, \& Turnovsky, 1981).
} 
the first economists to take up the debate over producers' preference for price instability. However, Oi's conclusion that producers prefer price instability to stability has created considerable controversy. Also, the effects of commodity storage to bring about price stability are unclear (Schmitz, 2018a). Oi considered only price instability that was created by demand shocks. Here, we extend the Oi result by including the case where price instability is generated by supply disturbances, and show that producers prefer price instability in production but not in consumption. We formulate a two-stage process, in which producers first produce a good and then generate additional gains through storage, which generates demand price stability.

\section{The Oi Result Revisited}

\subsection{Price Instability and Demand Fluctuations}

Figure 1(a) gives the basic Oi result as to why producers prefer price instability. Producer supply is given by $S$ and price instability is generated by fluctuations between $D_{1}$ and $D_{2}$ (this is the only case Oi considered). For demand $D_{1}$, the equilibrium price and quantity are $p_{1}$ and $q_{1}$. For $D_{2}$, the equilibrium price and quantity are $p_{2}$ and $q_{2}$. Producers prefer instability since they produce the largest quantity at the highest price. If the producers stored $q_{2} q_{u}$ in the high price period and released stocks $q_{1} q_{u}\left(=q_{u} q_{2}\right)$ in the low price period, they would suffer a welfare loss of $\left\{\left(p_{2} p_{u} a b\right)-\left(p_{u} p_{1} d a\right)\right\}$. This results in a net welfare loss from price stability of the shaded area $(e b a)$.

\subsection{Price Instability with Supply Fluctuations}

We broaden the discussion to consider the case where price instability is brought about by supply shocks. In the Oi result in Figure 1(a), when instability is brought about by demand shocks, producers have no incentive to store because of a high quantity, high price correlation. However, in Figure 1(b), when instability is generated by supply shocks, the high price $p_{2}$ is correlated with the low quantity $q_{2}$ and low price $p_{1}$ with high quantity $q_{1}$. Thus, there is a producer incentive to engage in storage.

In Figure 1(b), in the absence of storage, price instability is brought about by supply shocks $S_{1}$ and $S_{2}$. Demand is given by $D$. The expected prices and quantities are $p_{1}$ and $q_{1}$ in period 1 and $p_{2}$ and $q_{2}$ in period 2. As discussed below, producers gain from both price instability in production and from price stability in consumption.

\subsubsection{Producer Welfare: Price Instability with Zero Storage}

From Figure 1(b), producers prefer price instability over stability (Schmitz, 2018a, 2018b) as $\left\{\left(p_{1} b g\right)+\left(p_{2} a h\right)\right\}>2\left(p_{u} d c\right)$. The net welfare gain to producers is shown by the two different shaded areas $\left\{\left(f q_{u} q_{1} g\right)-(i e f c)\right\}$.

The conclusion that producers prefer price instability is with reference to our price instability model where the instability is generated by fluctuations in 


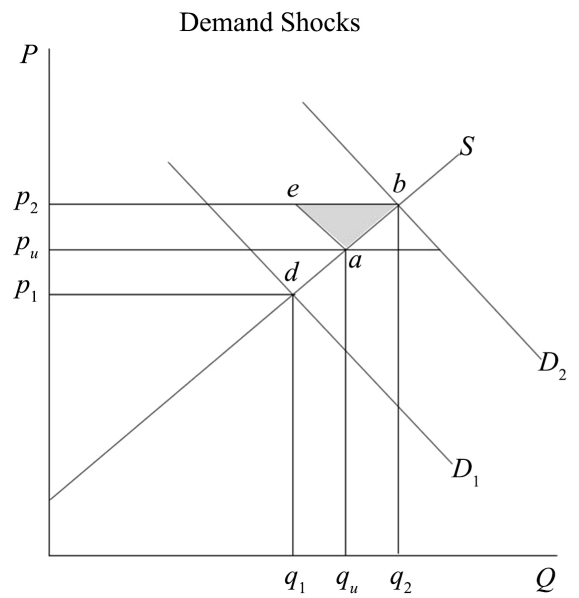

(a)

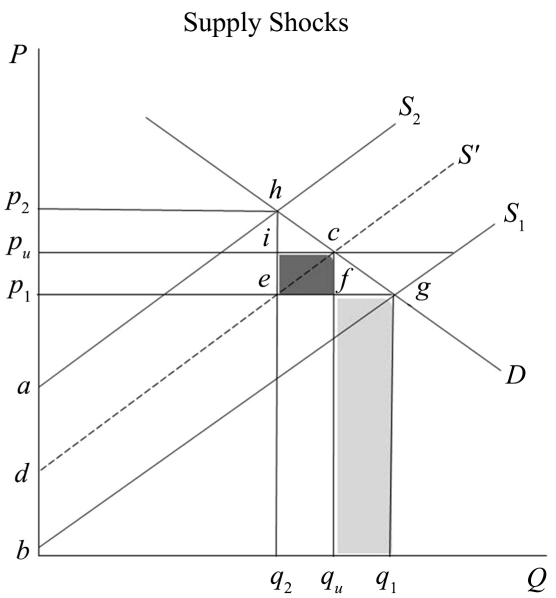

(b)

Figure 1. Producer preference for price instability under demand shocks and supply shocks.

supply $\left(S_{1}, S_{2}\right)$. This is compared to the stable price situation where, over both price periods, producers expect the same price and quantity. That is, the supply curve facing producers in each period is $S^{\prime}$.

\subsubsection{Producer Welfare: Price Stability with Storage}

In Figure 1(b), price instability is due to supplies $S_{1}$ and $S_{2}$ that generate quantities $q_{1}$ and $q_{2}$. In the absence of storage, the gain to producers from price instability is $\left\{\left(f q_{u} q_{1} g\right)-(\right.$ iefc $\left.)\right\}$. Now consider storage and its effect on price stability. Suppose that $q_{1} q_{u}$ is stored in period 1 and released in period 2. With storage, the consumption price is $p_{u}$ (but we emphasize that the consumption price is with reference to supply $S_{1}$ and $S_{2}$ and not $S_{0}$ ). Storage, in this case, stabilizes the consumption price, but not the production price. For $S_{1}$, there is a gain in total producer revenue as a result of storage, $\left\{\left(p_{1} p_{u} f c\right)-\left(q_{1} q_{u} g f\right)\right\}$. For $S_{2}$, there is a loss of $\left\{\left(p_{2} p_{u} i h\right)-\left(q_{2} q_{u} c i\right)\right\}$. Therefore, producers gain from price stability $2(i e f c)$ when storage stabilizes consumption but not production.

The producer gain from price stability due to storage is $\{($ iefc $)+($ iefc $)\}$. The gain from production instability is $\left\{\left(f q_{u} q_{1} g\right)-(i e f c)\right\}$. Therefore, the gains to producers from price stability is $\{(i e f c)+(i e f c)\}+\left\{\left(f q_{u} q_{1} g\right)-(i e f c)\right\}$. Even if one does not consider the gains from production instability, there is still a positive gain to producers from price stability.

Importantly, there is no need for government to undertake storage to create price stability since it is in the best interest of producers to engage in their own storage activities. However, this is often not possible in less developed countries where producers have inadequate storage. This is often why governments engage in storage activities.

\section{Conclusion}

Our conclusion that producers prefer price stability when price instability is due 
to price shocks is based on our framework where production decisions are independent of storage activities. Producers prefer price instability in production, but prefer price stability in consumption. In this context, storage is feasible, which was not the case in the earlier literature where producers consider production and storage as a joint activity in the production decision-making process (Massell, 1970).

There are several limitations to our analysis. First, uncertainty is not considered, and should be taken into account in future work. For example, a model could be developed, where using our above framework producers have a planning supply curve $S^{\prime}$ in Figure 1 (b) and $S_{1}$ and $S_{2}$ give the fluctuations in prices and quantities due to weather. Papers are needed that empirically demonstrate the magnitude of the gains and losses from producer price stability with commodity storage under both price certainty and uncertainty.

\section{Acknowledgements}

The author thanks G. Cornelius van Kooten, P. Lynn Kennedy, and Carol Fountain for comments.

\section{Conflicts of Interest}

The authors declare no conflicts of interest regarding the publication of this paper.

\section{References}

Kennedy, P. L., Schmitz, A., \& van Kooten, G. (2019). Food Security and Food Storage. Encyclopedia of Food Security and Sustainability, 2, 433-443. https://doi.org/10.1016/B978-0-08-100596-5.22251-8

Kennedy, P. L., Schmitz, A., \& van Kooten, G. C. (2020). The Role of Storage and Trade in Food Security: Evidence from India. Journal of Food and Industrial Organization, 18, Article No. 0056. https://doi.org/10.1515/jafio-2019-0056

Massell, B. F. (1970). Some Welfare Implications of International Price Stabilization. Journal of Political Economy, 78, 404-417. https://doi.org/10.1086/259637

Oi, W. Y. (1961). The Desirability of Price Instability under Perfect Competition. Econometrica, 29, 58-64. https://doi.org/10.2307/1907687

Schmitz, A. (2018a). Commodity Price Stabilization under Unattainable Stocks. Theoretical Economic Letters, 8, 861-865. https://doi.org/10.4236/tel.2018.85061

Schmitz, A. (2018b). Producers' Preference for Price Instability? Theoretical Economic Letters, 8, 1746-1751. https://doi.org/10.4236/tel.2018.810114

Schmitz, A. (2020). Commodity Storage, Price Stabilization, and Food Security. Journal of Food \& Industrial Organization, 18, Article No. 0053. https://doi.org/10.1515/jafio-2019-0053

Schmitz, A., \& Kennedy, P. L. (2016). Food Security and the Role of Food Storage. In A. Schmitz, P. L. Kennedy, \& T. G. Schmitz (Eds.), Food Security in a Food Abundant World: An Individual Country Perspective (pp. 1-18). Bingley: Emerald Group Publishing. https://doi.org/10.1108/S1574-871520150000016001 
Schmitz, A., Moss, C. B., Schmitz, T. G., Furtan, H. W., \& Schmitz, H. C. (2010). Agricultural Policy, Agribusiness, and Rent-Seeking Behaviour (2nd ed.). Toronto: University of Toronto Press.

Schmitz, A., Shalit, H., \& Turnovsky, S. J. (1981). Producer Welfare and the Preference for Price Stability. American Journal of Agricultural Economics, 63, 157-160. https://doi.org/10.2307/1239823

Turnovsky, S. J., Shalit, H., \& Schmitz, A. (1980). Consumers' Surplus, Price Instability, and Consumer Welfare. Econometica, 48, 135-152. https://doi.org/10.2307/1912022

van Kooten, G. C., Schmitz, A., \& Kennedy, P. L. (2020). Is Commodity Storage an Option for Enhancing Food Security in Developing Countries? Journal of Food and Industrial Organization, 18, Article No. 0054. https://doi.org/10.1515/jafio-2019-0054 